\title{
A SUBJETIVIDADE NOS DISCURSOS DA LITERATURA DE AUTOAJUDA*
}

\author{
THE SUBJECTIVITY IN SELF-HELP SUBJECTIVIDAD EN DISCURSOS \\ LITERATURE'S DISCOURSES DE LITERATURA DE AUTOAYUDA
}

\author{
Geilson Fernandes de Oliveira** \\ Universidade Federal do Rio Grande do Norte, \\ Programa de Pós-Graduação em Estudos da Mídia, Natal, RN, Brasil \\ Marcília Luzia Gomes da Costa Mendes*** \\ Universidade do Estado do Rio Grande do Norte, Departamento de Comunicação Social, \\ Programa de Pós-Graduação em Ciências da Linguagem, Mossoró, RN, Brasil
}

\begin{abstract}
Resumo: O presente artigo tem como objetivo refletir sobre a questão da subjetividade nos livros da literatura de autoajuda, de modo específico nas obras Treinando a emoção para ser feliz (2007a) e 12 semanas para mudar uma vida (2007b), ambas do escritor brasileiro Augusto Cury. Tomando como base a perspectiva teórica e metodológica da Análise do Discurso (AD) de orientação francesa, especialmente aquela desenvolvida na esteira dos estudos foucaultianos, são empreendidas discussões sobre a problemática. A partir de um processo de descrição e interpretação dos enunciados que compõem o corpus, identifica-se, nos discursos analisados, a mobilização de dispositivos e práticas da relação do sujeito consigo mesmo, os quais discursivizam e trabalham com a produção de subjetividades na contemporaneidade e inscrevem-se em um campo da produção editorial marcado por condições de possibilidades históricas e sociais dadas.
\end{abstract}

Palavras-chave: Discurso. Literatura de Autoajuda. Subjetividade.

Abstract: This paper aims to reflect on the question of the subjectivity in self-help literature books, particularly in Treinando a emoção para ser feliz (2007a) - Training Your Emotion To Be Happy, in English - and 12 semanas para mudar uma vida (2007b) - Twelve Weeks to Change Your Life, in English -, two works of the Brazilian writer Augusto Cury. Based on the theoretical-methodological perspective of the Discourse Analysis (DA), especially the one developed by Michel Foucault, we mobilize some discussions about this matter. From a process of description and interpretation of the statements that compose the

* Uma primeira versão deste texto foi apresentada durante a reunião do GP de Produção Editorial, no XXXVIII Congresso Brasileiro de Ciências da Comunicação - Rio de Janeiro, RJ, 2015. Aqui, são incorporadas algumas das discussões promovidas, assim como novos debates visando o enriquecimento e atualização da discussão empreendida.

** Doutor em Estudos da Mídia pela Universidade Federal do Rio Grande do Norte (UFRN). Membro do GEMINI - Análise e Pesquisa em Cultura, Processos e Produtos Midiáticos (UFRN) e do Grupo de Pesquisa Informação, Cultura e Práticas Sociais (UERN). ORCID: https://orcid.org/0000-0002-32784044. E-mail: geilson_fernandes@hotmail.com.

*** Doutora em Ciências Sociais pela Universidade Federal do Rio Grande do Norte (UFRN). Docente do Departamento de Comunicação Social e do Programa de Pós-Graduação em Ciências da Linguagem da Universidade do Estado do Rio Grande do Norte (UERN). ORCID: https://orcid.org/0000-0002-42327832. E-mail: marciliamendes@uol.com.br. 
corpus, we identified, in the analyzed discourses, the mobilization of devices and practices in the subject's relations with himself. Those devices discursivize and work with the production of subjectivities in the contemporaneity, as well as they are in a field of the editorial production marked by given conditions of social and historical possibilities.

Keywords: Discourse. Self-help literature. Subjectivity.

Resumen: Este artículo tiene como objetivo reflexionar sobre el tema de la subjetividad en los libros de literatura de autoayuda, específicamente en las obras Treinando a emoção para ser feliz (2007a) y 12 semanas para mudar uma vida (2007b), ambas del escritor brasileño Augusto Cury. Partiendo de la perspectiva teórica y metodológica del Análisis del Discurso (AD) con orientación francesa, especialmente la desarrollada a raíz de los estudios de Foucault, se emprenden discusiones sobre este tema. A partir de un proceso de descripción e interpretación de los enunciados que componen el corpus, se identifica, en los discursos analizados, la movilización de dispositivos y prácticas de la relación del sujeto consigo mismo, que discursan y trabajan con la producción de subjetividades en la época contemporánea, y se inscriben en un campo de producción editorial marcado por condiciones de posibilidades históricas y sociales dadas.

Palabras Clave: Discurso. Literatura de autoayuda. Subjetividad.

\section{A AUTOAJUDA, O CUIDADO DE SI E A PRODUÇÃO DE SUBJETIVIDADES: NOTAS INTRODUTÓRIAS}

$\mathrm{Na}$ atualidade, os discursos de autoajuda se têm espraiado de modo efetivo, de tal forma que sua presença na vida cotidiana é cada vez mais comum. Seja no jornalismo, seja nos modelos educacionais, nas mídias digitais ou em outros contextos, o discurso prescritivo e pedagógico da autoajuda está presente, orientando os sujeitos acerca de seus comportamentos e condutas a partir de modelos que visam guiar e fomentar normas e formas sobre uma vida estável, bem vivida e feliz. Como mecanismo constituinte da produção desses discursos, destaca-se com maior ênfase a literatura de autoajuda, segmento que, apesar das constantes crises do mercado editorial, continua a apontar números promissores, evidenciando, mais do que a força de um nicho específico, o sucesso dos discursos que ele produz junto a seu público.

Com ampla produção e circulação, tais discursos, fruto de condições de possibilidades sociais, históricas e culturais dadas, desvelam seu poder no engendramento de subjetividades, uma vez que suas narrativas tratam, para além de modelos de comportamento, de formas de cuidado do sujeito consigo mesmo, de sentir no que concerne aos acontecimentos que o rodeiam, bem como de conduzir sua própria vida, revelando o constante atravessamento destes discursos com a produção de sujeitos e subjetividades particulares no contemporâneo e a reconfiguração de práticas e técnicas inerentes a esse processo.

No que remete às discussões e problematização da noção de produção de subjetividades, tal temática foi tratada com especial atenção pelo filósofo francês Michel Foucault, especificamente quando de suas reflexões desenvolvidas durante os anos de 1970 e 1980, que se voltaram para a questão da constituição do sujeito e seus modos de subjetivação. Tais discussões são aqui de interesse considerando que os enunciados que constituem a autoajuda possuem, como será melhor visto quando da análise da empiria, uma relação direta com estas categorias. Segundo alguns leitores do filósofo francês, o 
estudo das relações citadas (sujeito e subjetividades) seria a terceira e última fase ${ }^{1}$ do pensamento foucaultiano, a qual teria como objetivo a análise dos modos pelos quais o sujeito se constitui enquanto tal a partir das relações estabelecidas consigo mesmo, isto é, de sua ética.

Para o autor, a ética de si estaria vinculada a um conhecimento de si mesmo, o qual é, conforme indica, necessário para a constituição do sujeito através de práticas que versam sobre um cuidado de si sobre si, mobilizando sua subjetividade e seus processos de subjetivação. É importante que não se confunda aqui o cuidado de si com o conhecete a ti mesmo, de Sócrates, pois são perspectivas distintas para se perceber a si mesmo. Foucault (1985) assinala que o conhece-te a ti mesmo seria um quadro mais genérico do cuidado de si, enquanto este último seria uma reflexão que não se limitaria ao conhecimento de si, mas a um cuidado ético aprofundado e indispensável.

Nas obras que constituem sua terceira fase, Foucault (1985) alerta que durante muito tempo as discussões relacionadas ao tema do cuidado de si não foram consideradas, trabalhadas ou desenvolvidas. Até a própria filosofia as desconsiderou por um certo período. Para ele, neste sentido, houve um "momento cartesiano", que favoreceu a emergência dos regimes discursivos/regimes de verdade sobre o sujeito, em oposição aos saberes sobre o cuidado de si.

O desenvolvimento das reflexões de Foucault sobre este tema recorre aos gregos e, mais tarde, aos romanos. Com o termo "cuidado de si", o teórico busca traduzir uma noção grega que perdurou por muito tempo: a epiméleia heautoú - em tradução, equivalente ao cuidado de si mesmo. Esta é uma noção rica e complexa, que indica a ocupação do sujeito consigo mesmo visando ao aprimoramento de sua existência a fim de produzir uma vida da forma mais bela possível.

Por indicar a preocupação do sujeito para consigo mesmo, o cuidado de si se mostra como uma prática extremante importante para a história do sujeito e de sua subjetividade, ou, para a história de suas práticas de subjetividade. A adesão às práticas de si é vista como o momento do primeiro despertar, referindo-se ao fato de que o sujeito abre os olhos e abandona seu sono, passando a ter interesse pela ocupação consigo mesmo.

Segundo a epiméleia heautoú grega, é necessário que o sujeito se ocupe consigo mesmo, possibilite reflexões sobre suas inquietações e suas ações. Por este motivo, os aspectos da epiméleia heautoú deveriam fazer parte das práticas cotidianas dos sujeitos. "O cuidado de si é uma espécie de aguilhão que deve ser implantado na carne dos homens, cravado na sua existência, e constitui um princípio de agitação, um princípio de movimento, um princípio de permanente inquietude no curso da existência" (FOUCAULT, 2006, p. 11). As reflexões sobre o cuidado de si elaboradas por Foucault explanam as "técnicas de si", por meio das quais os sujeitos se constituem. Como parte efetiva do cuidado de si, estas técnicas permitiriam aos sujeitos efetuarem, por si próprios, operações e análises sobre seus corpos, seus pensamentos, condutas, suas próprias almas.

\footnotetext{
1 Alguns pensadores que se dedicam ao estudo da obra foucaultiana dividem seus escritos em três fases/momentos: a arqueologia, voltada para a relação entre discursos, saberes e a história; a genealogia, voltada para a análise das relações de poder, e a fase da ética ou do cuidado de si, na qual o filósofo dedica especial atenção para as formas de subjetivação, cuidado e governo dos sujeitos. No entanto, esta divisão recebe algumas críticas, sendo a principal a que defende a não existência dessa divisão na obra do autor, uma vez que seria possível identificar uma imbricação de todos os temas acima mencionados em todos os seus escritos.
} 
Diante dos elementos explicitados, neste artigo são promovidas análises e reflexões sobre a relação da literatura de autoajuda, em específico dos enunciados que compõem nosso corpus - as obras Treinando a emoção para ser feliz (2007a) e 12 semanas para mudar uma vida (2007b), ambas do escritor brasileiro Augusto Cury ${ }^{2}$ - com o ocupar-se consigo mesmo, ou seja, com a questão da atenção e cuidado do sujeito sobre si, atentando para a produção de subjetividades daí advindas, considerando que estes discursos trabalham efetivamente com a promoção de formas e normas no que concerne a modos de ser, estar e se comportar, fornecendo modelos subjetivos. Para tanto, são tomados como base os postulados teóricos e metodológicos da Análise de Discurso de orientação francesa, especialmente aquela que vem sendo desenvolvida na esteira dos estudos foucaultianos.

\section{A LITERATURA DE AUTOAJUDA}

O tipo de literatura que deu origem ao gênero autoajuda formou-se a partir de transformações sociais, históricas e culturais que possibilitaram mudanças na percepção sobre o poder da mente, decorrente, especialmente, da difusão da cultura de massa, como sugere Rüdiger (1996). O fenômeno literário teve como percussor expressivo um livro homônimo ao título do gênero: Self-Help (autoajuda), do médico e publicista Samuel Smiles, em 1859.

A obra consiste em uma série de palestras proferidas pelo autor para um grupo de trabalhadores que tinham aprendido a ler e a escrever, além de estudar outras disciplinas de forma autônoma. A partir de Self-Help, Smiles buscava mostrar aos leitores o quanto nós podemos ajudar a nós mesmos e, principalmente, o quanto "a felicidade e o bem estar individuais do decurso da vida dependem principalmente e necessariamente de nós" (SMILES, 1859 apud RÜDIGER, 1996, p. 33).

Com proposta inovadora para a época, esta é a obra de maior sucesso de Smiles, que também produziu outros livros com temática semelhante ${ }^{3}$. Self-Help já foi publicado em várias línguas e é apontado como a obra que inaugura uma nova lógica, transmitindo os princípios que qualquer pessoa deveria e poderia buscar por seus objetivos, fazendo uso da perseverança e de seus esforços individuais, abandonando qualquer tipo de amparo ofertado pelas culturas precedentes.

Como parte da lógica da indústria cultural, a autoajuda é vista como uma das instâncias propagadoras da felicidade, estado que se torna, ele mesmo, uma indústria em

\footnotetext{
${ }^{2}$ A escolha das obras deste autor dá-se pelo fato de seus livros como um todo já terem vendido mais de 20 milhões de exemplares somente no Brasil e terem sido publicados em mais de 70 países. Além disso, Augusto Cury foi considerado pela Folha de S. Paulo e Revista Isto É o autor mais lido no Brasil na primeira década do século XXI e, recentemente, como o brasileiro que mais vende livros no país, segundo a Época Negócios, conforme informações publicadas nos seguintes endereços: http://www1.folha.uol.com.br/folha/ilustrada/ult90u600189.shtml, http://www.istoe.com.br/reportagens/142655_O+MAIOR+VENDEDOR+DE+LIVROS+DO+BRASI L e https://epocanegocios.globo.com/Vida/noticia/2018/01/augusto-cury-o-brasileiro-quemaisvende-livros-no-brasil-quer-desacelerar.html. Acesso em: 2 mar. 2021.

${ }^{3}$ O poder da vontade (1865), O Caráter (1875) e O dever (1880).
} 
crescimento. Schoch (2011, p. 11) demonstra a extensão dessa indústria em valores monetários, apontando que "os livros de autoajuda geram vendas de US\$1 bilhão anualmente [...]". Nesse cenário, o Brasil é, conforme Tucherman (2012), o segundo maior público consumidor do gênero. Afunilando essa discussão, Freire Filho (2010) mostra que, de acordo com dados da Câmara Brasileira do Livro (CBL), consultados por ele em 2010, o segmento da literatura de autoajuda cresceu, no país, de 5\% a 10\% ao ano, entre 1996 e 2006. Conforme esses dados, no ano de 2006 cerca de 600 novos livros do gênero foram lançados, compreendendo, inclusive, obras direcionadas ao público infantil.

Ainda, segundo pesquisa realizada pela Associação Nacional de Livrarias (ANL, 2012), os livros desse segmento apresentam-se na quarta posição da lista de classificação dos gêneros mais comercializados no Brasil, demonstrando, além disso, que, de 2009 para 2012, a comercialização dessas publicações teve $23 \%$ de crescimento, percentual ainda mais expressivo em relação aos apresentados por Freire Filho em 2010. Mesmo em tempos de crise editorial, é um gênero que continua em ascensão ${ }^{4}$, sobretudo em momentos de crise política e econômica ${ }^{5}$, como a vivida no tempo presente. Estas obras não apresentam formato somente de livros impressos, mas atendem à dinâmica do mercado, sendo produzidas e vendidas em diversos outros suportes, como ocorre com os livros digitais e os audiolivros.

Para se ter uma noção da popularidade e sucesso do gênero autoajuda, desde 1983 o New York Times criou estrategicamente uma forma de divulgar a lista dos livros mais vendidos, criando uma nova categoria - Advice (conselho) -, seção que se tornou especial para os livros de aconselhamento. A necessidade de sua criação mostrou-se importante e justificável, pois, como afirma Tucherman (2012, p. 137), "se isso não fosse feito, nunca mais nenhum livro de não ficção poderia aparecer como sendo um dos mais vendidos". Esta mesma estratégia foi tomada como modelo pela Revista Veja a partir de 1989 e, na sequência, por muitas outras empresas.

Renúncia não é palavra recorrente nos ideais de vida da "civilização do desejo" (LIPOVETSKY, 2007); a ordem é o principio do gozo, da felicidade, a liberação do homem de todo e qualquer passado de carências, sofrimentos e inibição. Neste contexto, a autoajuda, com seu discurso prescritivo, intitula-se como um dos dispositivos que possuem as fórmulas para esse bem-estar, agenciando muitos tipos de aconselhamento. O gênero fornece esquemas e/ou etapas a serem cumpridas, atestando que através de seu exercício levarão o sujeito ao patamar almejado (MENDES; OLIVEIRA, 2013).

Do sucesso na carreira profissional ao êxito amoroso, as obras colocam em cena o discurso de que não existe mais nenhum domínio da existência humana que não possa ser aprimorado. Assim, fornecem a uma massa de leitores ávidos novas estratégias e técnicas de fácil compreensão, objetivando maximizar sua existência subjetiva. A felicidade torna-

\footnotetext{
${ }^{4}$ De acordo com o balanço de vendas de livros feito pelo "Painel das Vendas de Livros no Brasil", houve aumento significativo nas vendas de livros de autoajuda entre 2016 e 2017. Segundo os dados, houve um crescimento acumulado de 4,55\%, o que corresponde a aproximadamente 1 milhão e 800 mil exemplares, conforme informações disponíveis em: https://snel.org.br/levantamento-mensal/ Acesso em: 02 mar. 2021.

5 Conforme disposto em: https://veja.abril.com.br/entretenimento/autoajuda-um-segmento-que-floresceem-tempos-de-crise/ Acesso em: 2 mar. 2021.
} 
se, então, um imperativo (BIRMAN, 2010), ao mesmo tempo que surge uma indústria do bem-estar e do aprimoramento pessoal, originando o que Freire Filho (2010) denomina técnicas da felicidade. Para esse autor, vivemos na era da reprodutibilidade científica da felicidade, em que existe um verdadeiro império dos manuais de autoajuda, nos quais a manifestação da certeza é um dos traços semânticos.

A literatura do gênero é formada por manuais e textos práticos, os quais indicam métodos e formas de bem viver, obter sucesso material - riqueza, trabalho, etc. -, e sucesso pessoal - felicidade, emagrecimento, encontro de parceiros amorosos, superação da timidez, etc. Também podem ser encontrados neste gênero relatos pessoais, com histórias de vida de sucesso - material e pessoal -, apresentando as maneiras utilizadas para superar as adversidades e tornar-se uma "nova pessoa" (RÜDIGER, 1996). Nas obras, o pressuposto básico é a noção de que o bem-estar subjetivo será alcançado através de um "condicionamento positivo" e disciplinamento pessoal que resultará em uma verdadeira transformação.

\begin{abstract}
Os programas de autoajuda partem dessa convocação primeira à transformação de si. Variam conforme a necessidade dos públicos segmentados. Essa "necessidade" nem sempre vem do mundo cultural para ser atendida pelos tecnólogos de discursos ou analistas simbólicos, que concebem os formatos e programas de autoajuda. Por vezes essa necessidade está latente até ser descoberta pelos tecnólogos e, uma vez descoberta e lançada num formato, seja televisivo, seja ciberespacial, ela parece inevitável, ou seja, algo que teria de ser tido despertado de modo ou outro, pois, a partir dela, o mundo já não parece ser o que era. (PRADO, 2013, p. 12)
\end{abstract}

São livros que atendem às demandas latentes e obtêm, por consequência, grande sucesso de público, tendo em vista seu "pedagogismo", isto é, mensagens que visam a adequar o sujeito leitor aos discursos dominantes, tranquilizá-los por meio dos sentidos produzidos, torná-los “melhores”. Os títulos da literatura de massa - e aqui enquadramos a autoajuda -, são manifestações de um discurso que é resultante das tendências e exigências geradas pela sociedade moderna. Uma prova disto, defende Sodré (1988), é que a indústria editorial responsável pelas publicações desse tipo investe continuamente neste nicho já há algum tempo, sem ainda demonstrar ter sofrido prejuízo. Basta olharmos a quantidade de títulos lançados para repararmos esta questão.

No Brasil, um dos autores mais lidos e que mais vende, segundo o Jornal Folha de S. Paulo, Revista Isto É e Época Negócios, por exemplo, é Augusto Cury, escritor conhecido por suas inúmeras obras de aprimoramento pessoal. Uma delas - $O$ vendedor de sonhos -, inclusive chegou aos cinemas em 2016 após ter sido transformada em filme, o que desvela o potencial comercial e simbólico dos discursos produzidos por suas obras. Os livros do autor já foram publicados em mais de 60 países, sendo traduzidos para diversos idiomas e vendendo mais de 16 milhões de exemplares somente no Brasil.

\title{
3 A INSCRIÇÃO DA SUBJETIVIDADE NOS DISCURSOS DA LITERATURA DE AUTOAJUDA
}

Como é apontado por Thompson (1998), com o advento dos meios de comunicação e a profusão de seus produtos, o eu, visto como projeto simbólico ou self, é atingido diretamente pelos conteúdos produzidos por estes meios, de modo que os sujeitos muitas 
vezes são influenciados e a partir deles passam a orientar as suas ações. Ao mesmo tempo, o self torna-se mais reflexivo, já que os sujeitos, a partir da forte expansão dos recursos simbólicos disponíveis, são continuamente confrontados com as possibilidades que lhes são apresentadas. Com isto, há a promoção de formas alternativas para uma reflexão crítica de si mesmo.

\begin{abstract}
A profusão de materiais simbólicos pode fornecer aos indivíduos os meios de explorar formas alternativas de vida de um modo imaginário e simbólico; e consequentemente, permitir-lhes uma reflexão crítica sobre si mesmos e sobre as reais circunstâncias de suas vidas (THOMPSON, 1998, p. 185)
\end{abstract}

Neste sentido, como parte destes "materiais simbólicos", os discursos da literatura de autoajuda podem atuar no sentido de promover mais reflexões sobre o sujeito em relação a si mesmo, compreendendo que o leitor deste gênero busca medidas paliativas para lidar com as agruras enfrentadas em seu cotidiano, atuando, dessa forma, em sua subjetividade.

Por uma perspectiva mais integrada (ECO, 1979) e deixando de lado análises meramente mercadológicas e/ou ideológicas sobre o fenômeno da literatura de autoajuda, observa-se que com seu advento os sujeitos que, em seu dia a dia, não dispõem de tempo para refletir sobre suas vidas e sobre si mesmos são instados a refletir sobre sua existência, como propõe Giddens $(2002 ; 1991)$. Esta reflexão é proposta e pode se efetivar, principalmente, a partir de enunciados que versam sobre a necessidade de uma maior atenção do sujeito por si mesmo, como é identificado quando da análise da empiria:

\footnotetext{
$\mathrm{SD}^{6} 1$ - Ache tempo para se ouvir e falar de você [...] Quantas vezes você faz uma pausa e reflete sobre sua vida? Quantas vezes você consegue desfazer seus compromissos e acha espaço para refletir sobre os pilares de sua existência? Muitos são ótimos para trabalhar, mas péssimos para cuidar de si mesmos. Eles têm tempo para tudo, mas não para dialogar consigo mesmos (CURY, 2007a, p. 87).

SD 2 - Podemos fugir do mundo, mas não de nós mesmos. Para escrever nossa história precisamos conhecer nosso próprio ser (CURY, 2007b, p. 31).
}

Com efeito, os enunciados acima destacados sugerem ao leitor uma maior reflexão e conhecimento do sujeito por si mesmo, promovendo modulações subjetivas que versam sobre uma maior interiorização e atenção sobre si em meio às atribulações diárias. Em sua exterioridade, há a produção discursiva de sujeitos e subjetividades, especialmente por meio da proposta de uma conversão para si, o que implica uma reflexão, autodiálogo e autoconhecimento, ou seja, discursiviza-se sobre uma produção subjetiva de si sobre si. Nestes enunciados, são produzidos sentidos que propõem a necessidade da ação por parte do sujeito, negando sua pretensa passividade e entrando em ação, por sua vez, a dimensão da subjetividade e do sujeito como uma produção constante.

No que diz respeito à relação estabelecida com os leitores, sujeitos produzidos também por estes discursos, identifica-se uma positividade nesses enunciados ao

\footnotetext{
${ }^{6}$ Sequência Discursiva.
} 
intermediarem e proporem um conhecimento sobre o próprio ser. Assim, de acordo com esta perspectiva, que deixa de lado as análises que versam sobre um princípio alienante das relações de poder intrínsecas aos produtos da indústria cultural, esta seria uma positividade do poder, que contraria o sentido do poder como algo somente negativo, como afirma Foucault (2013a):

\begin{abstract}
Ora, me parece que a noção de repressão é totalmente inadequada para dar conta do que existe justamente do produtor no poder. Quando se define os efeitos de poder para repressão, temse uma concepção puramente jurídica deste mesmo poder; identifica-se poder a uma lei que diz não. $O$ fundamental seria a força de proibição. Ora, creio ser esta uma noção negativa, esquelética do poder que curiosamente todo mundo aceitou. Se o poder fosse somente repressivo, se não fizesse outra coisa a não ser dizer não você acredita que seria obedecido? $\mathrm{O}$ que faz com que o poder se mantenha e que seja aceito é simplesmente que ele não pesa só como uma força que diz não, mas que de fato ele permeia, produz coisas, induz ao prazer, forma saber, produz discurso. Deve-se considerá-lo como uma rede produtiva que atravessa todo o corpo social muito mais do que uma instância negativa que tem por função reprimir (FOUCAULT, 2013a, p. 44-45).
\end{abstract}

Como uma rede produtiva, as relações de poder presentes nos discursos mencionados atuam também na produção de sujeitos e subjetividades, possibilitada pelo condicionamento a partir da relação de reflexão estabelecida entre o sujeito leitor e os enunciados. Na perspectiva de Rüdiger (1996), a literatura de autoajuda se constitui como uma das principais mediações da vida social contemporânea, uma vez que, por meio de seus discursos, as pessoas comuns, independente de classes, são atraídas tendo como objetivo aprimorar, por meio da leitura e dos sentidos que são produzidos e reproduzidos, sua existência e sua subjetividade. A mitologia euforizante expressa é, de certo modo, indica Morin (1997), o antídoto para a angústia difusa dos novos tempos.

Assim sendo, o poder deve ser pensado por uma perspectiva não puramente negativa, bem como os discursos de autoajuda, pois eles também são produtores e engendram sujeitos e subjetividades específicas. Neste sentido, ao mesmo tempo que se propõem a disciplinar, as relações de poder instituídas juntamente com o discurso de superação e da felicidade como um imperativo (FREIRE FILHO, 2010), que colocam à margem o seu contrário, podem engendrar o interesse pelo cuidado de si, bem como intensificar, após a leitura, as relações de si para consigo e contribuir para uma política de si. Ressalta-se, no entanto, que essas afirmações não pretendem ser deterministas ou universais, levando em conta a singularidade de cada relação que é/pode ser estabelecida com os enunciados analisados ${ }^{7}$.

Nos ideais do cuidado de si por meio da efetivação das técnicas de si para consigo, o sujeito poderia caminhar e atingir um estado de perfeição. Estas técnicas contribuiriam para a elaboração de uma arte da existência. Referindo-se às artes da existência, Foucault (2006) apresenta a noção das práticas refletidas pelos próprios sujeitos, técnicas de si,

\footnotetext{
${ }^{7}$ Considerando que este artigo é alicerçado na análise do discurso, isto é, na análise dos enunciados, não se pode definir categoricamente os efeitos dos discursos da autoajuda, sendo necessário, para tanto, estudos sobre a recepção do tipo de literatura analisada. Por este motivo, justifica-se o uso das palavras "podem" e "pode", tendo em vista que a análise é centrada na reflexão da relação entre discurso e engendramento de subjetividades, como propõem estudos recentes do campo da AD francesa.
} 
logo, artes que os aproximariam da perfeição. Através destas artes, o homem não somente fixava regras de conduta (discurso e prática), mas buscava se transformar e fazer de sua vida, de sua existência, uma obra de arte, “[...] no sentido de uma arte de viver entendida como cuidado de si, de uma elaboração da própria vida como uma obra de arte, da injunção de um governo da própria vida que tinha por objetivo lhe dar a forma mais bela possível" (MACHADO, 2013, p. 34).

Ao abordar o conceito de estética da existência, o autor explicita que se trataria de um processo de autodescoberta dos valores de si, de autoconhecimento, no qual o sujeito poderia se constituir enquanto tal através do aprimoramento de si mesmo. O cuidado de si é visto, então, como uma arte da existência (FOUCAULT, 1985, p. 50).

\begin{abstract}
As "artes da existência" devem ser entendidas como as práticas racionais e voluntárias pelas quais os homens não apenas determinam para si mesmo regras de conduta, como também buscam transformar-se e modificar seu ser singular, e fazer de sua vida uma obra que seja portadora de certos valores estéticos e que corresponda a certos critérios de estilo (FOUCAULT, 1985, p. 198-199).
\end{abstract}

Neste processo, o filósofo pontua a importância das relações entre o discurso e a prática como um dos critérios necessários para o cuidado de si e um estilo de vida, defendendo que o cuidado de si não se caracteriza como um exercício solitário, mas de ordem social, no sentido de que não basta afirmar por meio do discurso a busca pelo autoconhecimento, mas, de modo mais importante, sua prática, fator que possibilitará o convívio consigo mesmo (governo de si) e com os outros (governo de si e dos outros). É neste sentido que ele retoma o conceito de parrhesia como um procedimento técnico fundamental para o cuidado de si (FOUCAULT, 2006).

A parrhesia é definida como o dizer verdadeiro, o franco falar. Um aspecto de maior relevo deste conceito está ligado à questão da coerência entre o dizer/discurso com a própria vida. Logo, sua relação com o cuidado de si é colocada pela necessária articulação que deve existir entre o discurso e a prática, bem como a necessidade de conhecer-se verdadeiramente, de modo parrhesiástico, podendo ser inclusive por meio das práticas de veridicção e/ou os jogos de verdade de si para consigo. Em sua Hermenêutica do sujeito, Foucault pontua incisivamente que a parrhesia é útil para a "gerência" da alma (FOUCAULT, 2006, p. 488). Percebe-se, assim, o papel relevante da parrhesia, bem como do parrhesiasta - aquele que diz a verdade, fala francamente e dirige seu aprendiz para o caminho do conhecimento que propiciará o autoconhecimento e modificação do seu ser -, no estabelecimento das relações de si para consigo, para a construção de uma estética da existência. A partir das análises e reflexões sobre a empiria, observa-se que Cury mostra-se, por meio dos enunciados e discursos que produz, como um "novo" parrhesiasta, uma vez que se coloca como aquele que diz a verdade ou fornece as orientações sobre o bem viver. Com efeito, o posicionamento assumido se dá como resultante das contingências históricas atuais, sendo, evidentemente, distinto daquele da antiguidade.

As artes da existência apresentadas por Foucault quando da análise das práticas greco-romanas do cuidado de si, nas quais a parrhesia seria parte efetiva, extrapolam o âmbito do conhece-te a ti mesmo. Mais do que isso, pressupõe um governo de si por si 
mesmo, por meio do qual o sujeito deve e pode examinar-se, refletir sobre si mesmo e se reparar diante das necessidades, de modo a poder constituir um trajeto de sua própria vida, fundada em preceitos de uma ética de si, podendo compor, deste modo, um quadro o mais belo possível de si mesmo. Todavia, nas práticas parrhesiásticas o outro é de grande importância, já que ele pode ser aquele que diz a verdade, fala francamente e induz o sujeito a uma relação de si para consigo, a um governo de si ético e verdadeiro.

Cabe a este outro, dessa forma, antes de tudo saber governar a si mesmo para poder proceder ao governo dos outros e incentivar um governo de si. A partir das relações que estabelece, Augusto Cury produz-se discursivamente como um parrhesiasta da atualidade, demonstrando saber governar a si mesmo, possuindo conhecimentos necessários e suficientes (formação, escritor de vários livros de sucesso e criador da teoria da inteligência multifocal ${ }^{8}$ e de técnicas - PAIQ ${ }^{9}$, D.C.D. ${ }^{10}$, etc.) para atuar tanto no governo de si, como também no dos outros, o que é visto como uma estratégia discursiva, pois a partir disso o autor se propõe como uma autoridade, que, com seu saber e experiência (SD 3), vontade e produção de verdade sobre os caminhos da felicidade, indica as rotas a serem seguidas para o encontro consigo mesmo e com uma vida estável e feliz, como ocorre quando da indicação da necessária análise sobre o tempo dedicado pelo sujeito leitor para uma conversa consigo mesmo (SD 4), colocando este aspecto como um elemento significativo, bem como quando enuncia críticas no que remete aos modos de existência que não têm contribuído para uma vida satisfatória (SD 5).

SD 3 - Muitos nos têm enviado e-mails dizendo que suas vidas ganharam novos rumos após a leitura (CURY, 2007a, p. 117).

SD 4 - Converse, debata e discuta aberta e silenciosamente consigo mesmo. Interiorize-se. Seja seu grande amigo. Analise se você tem tido tempo para todo mundo, mas não para si mesmo (CURY, 2007b, p. 187).

SD 5 - Critique seus paradigmas existenciais, seus conceitos sobre a vida. Repense suas verdades e seus comportamentos rígidos (CURY, 2007a, p. 105).

Esta característica é fortalecida, ainda, quando o autor discorre sobre os relatos de seus leitores ou pacientes, evidenciando nestes uma mudança após a adoção das técnicas

\footnotetext{
${ }^{8}$ Título de outra obra de Cury - Inteligência Multifocal, São Paulo, Cultrix, 1998, que chega a ser citada e indicada para os leitores nas obras analisadas. Segundo Cury, a inteligência multifocal diz respeito a uma teoria que tem sido estudada por diversos cientistas em vários países, chegando inclusive a ser inserida nas grades curriculares de alguns cursos universitários. É uma teoria que investiga os fenômenos da inteligência humana a partir de quatro processos da psique ou mente humana: " $1-a$ formação de pensamentos; 2 - a transformação da energia psíquica; 3 - a formação da consciência e dos alicerces do "eu"; 4 - os papéis da memória e a formação da história existencial" (CURY, 2007b, p. 20).

${ }^{9}$ O PAIQ é o Programa da Academia de Inteligência de Qualidade de Vida. É através desse programa que o autor indica os passos e técnicas necessárias para se atingir o bem-estar e a felicidade.

${ }^{10}$ Técnica proposta por Cury, o D.C.D. (Duvidar, Criticar, Determinar). É trabalhada a partir das seguintes práticas: a necessidade de o sujeito leitor duvidar de sua incapacidade, criticar sua passividade e determinar novos rumos para sua vida a partir de um "choque de lucidez na emoção".
} 
por ele sugeridas, reforçando seu estatuto de sujeito que diz uma verdade que é comprovada e empiricamente validada:

SD 6 - J.C. passou por onze psiquiatras. Fui o décimo segundo e, felizmente, o último. Ele compreendeu as causas do seu transtorno obsessivo e principalmente aprendeu a criticar seus pensamentos e a dar um choque de lucidez na sua emoção (CURY, 2007a, p. 29).

SD 7 - J.N. fez esse treinamento. O resultado? Libertou sua emoção do cárcere. Reacendeu as chamas de sua segurança e expandiu as raízes de sua autoestima [...]. Depois de percorrer um solitário deserto, J. N. se tornou um poeta da emoção. Hoje, é um homem feliz e sábio (CURY, 2007a, p. 86)

Verifica-se, então, o quanto o autor se postula como alguém que é detentor de um saber, um mestre da experiência, legitimado para a atuação no que concerne a orientações e aconselhamentos.

Conforme Marín-Diaz (2015), a autoajuda se ancora nos ideais de um governo de si, tal qual propõe os preceitos do cuidado de si, sendo, no entanto, um dispositivo renovado ou atualizado de técnicas mais antigas que tinham como meta a sabedoria ou um estado de si elevado. Tais questões são identificadas, como indicam as materialidades destacadas, haja vista o trabalho com a proposta de uma percepção mais apurada e uma interiorização que dê conta de uma avaliação sobre os modos de vida do sujeito leitor, o que é feito com a indicação de que este possa repensar verdades e comportamentos a partir de uma autoanálise, mobilizando ações que possuem um caráter estritamente subjetivo.

$\mathrm{Na}$ contemporaneidade, ainda segundo Marín-Diaz (2015), o dispositivo da autoajuda e suas técnicas atuam visando a felicidade e o bem-estar. Com a atualização dos contornos históricos e sociais dos dispositivos do cuidado de si, modificam-se as técnicas, assim como seus resultados. Evidenciando-se como um dispositivo produtor de subjetividade no presente, verifica-se, conforme assevera a autora,

[...] a ancoragem da autoajuda numa milenar tradição de práticas dirigidas para o governo de si. Trata-se de um conjunto de técnicas antigas como a meditação e a escrita de si que são agora atualizadas num dispositivo novo [...]. Este dispositivo precisa de indivíduos, isto é, para funcionar requer produzir indivíduos que ajam como "eus", com interesses e com capacidade de aprender a aprender, para atingir a nova meta desejável: ser bem-sucedidos e felizes (MARÍN-DIAZ, 2015, p. 9).

Frente a estas questões, por meio dos processos de descrição e interpretação dos enunciados, o fenômeno da autoajuda é percebido como uma das tecnologias de si contemporâneas que se propõem a promover, através de seus discursos, uma relação de maior atenção do sujeito consigo mesmo, incidindo, desta forma, diretamente em suas produções subjetivas. Por tecnologias do eu, Foucault (2006) visava definir as práticas que permitiam ao indivíduo efetuar, por si próprio ou com a ajuda de outros, operações sobre seu corpo e sua alma, a fim de se transformar e alcançar um estado de sabedoria. 
Com respaldo nos escritos de Deleuze (2008), que tiveram influência das noções elaboradas por Foucault, a relação entre autoajuda, tecnologias, cuidado e governamento de si se dá, com efeito, pela concepção de que "houve uma experiência grega, experiências cristãs, etc; mas, não são os gregos nem os cristãos que farão a experiência por nós hoje" (DELEUZE, 2008, p. 132). Neste sentido, tomar a autoajuda como uma tecnologia de si que engendra a produção de subjetividades e governamento de si não se dá a partir de uma visão de evolução ou retrocesso desses conceitos, mas uma necessidade de analisar o campo sócio-histórico como descontínuo, com desníveis e fissuras que favorecem as condições de possibilidade de outras tecnologias de si, cuidados e governamentalidade no decorrer da história e, por conseguinte, as transformações pelas quais passaram os modos de subjetivação hoje existentes, pois "não são os gregos, é nossa relação com a subjetivação, nossas maneiras de nos constituirmos como sujeito" (DELEUZE, 2008, p. 132), especialmente pelo fato de que ser contemporâneo é viver em um presente onde jamais estivemos, cabendo, desta forma, sua análise, pois, como pontua Revel (2006), "não se trata de se tornar novamente gregos, nem de pensar que eles foram mais admiráveis do que nós. Trata-se, precisamente, de compreender o que nós não somos mais, a fim de nos perguntar, ao contrário, o que nós somos hoje" (REVEL, 2006, p. 23), em que relações estamos inseridos e de que modos nossas subjetividades se têm produzido.

Reconhece-se, deste modo, que, por sua forma e visando ao aprimoramento contínuo dos sujeitos, bem como o fato de poder propiciar a partir dos momentos de leitura um momento de reflexão, os discursos da autoajuda são tecnologias de si da atualidade que proporcionam outras subjetividades, podendo vir a induzir em algum momento um estado de si semelhante ao expresso pelo cuidado de si, mas não nos moldes da epiméleia heautoú grega, tendo em vista outras condições de produção e relações que ora se estabelecem, bem como se considerando as lógicas e interesses inerentes ao gênero autoajuda e suas articulações com a dinâmica da indústria cultural, padrões morais atualmente em voga e suas relações de saber e poder.

Fazendo uso dos preceitos foucaultianos, Mansano (2009) destaca a importância da análise do presente e de seus dispositivos na constituição da história e a desvalidação de qualquer pensamento que queira se fazer universal. Em suas palavras,

\footnotetext{
Seguindo a investigação sobre os modos de subjetivação, cabe perguntar: quais modos de vida precisam ser abandonados e quais outros pedem passagem em nossos dias? Qual a potência que temos para produzir outros modos de existir e colocá-los em circulação no social? É perceptível o quanto os estudos de Foucault convocam para uma análise do presente e das nossas possibilidades de transformação. Para isso, ele resgata a dimensão histórica que atravessa os modos de subjetivação, descartando, assim, qualquer pretensão de universalidade. (MANSANO, p. 114, 2009)
}

Torna-se válido salientar, neste sentido, que esta produção de subjetividades promovida pelos discursos de autoajuda não se dá de forma determinante e muito menos universal, como são apregoados pelos discursos deste tipo de literatura, levando em conta a multiplicidade de sujeitos e subjetividades, que, no encontro com as estimulações variadas, produzem uma miscelânea de outras subjetividades, as quais nunca são 
passíveis de totalização e/ou implicam posse; ao contrário, são uma produção incessante que acontece através de encontros e desencontros diversos. A autoajuda, como prática contemporânea de subjetivação, agencia sujeitos, identidades, modos de ser e estar. Com efeito, seus discursos fornecem e possibilitam a produção e o agenciamento de subjetividades a partir da exterioridade de que se constitui.

Nesse sentido, os discursos produzidos por Cury reatualizam antigas práticas de cuidado e atenção por parte dos sujeitos, o que é feito em meio a interesses, lógicas e processos bem distintos, haja vista os preceitos econômicos alicerçados na racionalidade neoliberal a que muitas vezes obedecem, mas, mesmo assim, com atuação na modulação de uma subjetividade que deve voltar o olhar para si mesma, conforme sugerido nas sequências discursivas destacadas, o que é verificado nas obras desde seus títulos e reiterado no decorrer de seu desenvolvimento, reforçando o interesse em promover nos leitores uma autoavaliação, redirecionamento e mudança de postura que possa ser favorável e proporcionar uma vida estável e feliz, elementos na grande maioria das vezes colocados de forma imperativa, desvelando que o regime de cuidado e atenção que é discursivizado e proposto é atravessado por uma ética e modelo moral particulares e correspondentes a seu tempo. Nessa perspectiva, tomando a subjetividade como uma produção essencialmente modelada e fabricada social e historicamente, a autoajuda, como tecnologia de si, se propõe a impulsionar esta relação do sujeito consigo mesmo, o que é feito em meio a seus diversos atravessamentos.

No que diz respeito a este processo de conversão do olhar e produção constante do sujeito e suas subjetividades, tal aspecto é indicado por Foucault (2006), que visualiza o sujeito como uma produção incessante e um agente estratégico e não imóvel ou somente instado e gerenciado pelos poderes que circulam no social, elemento que é reforçado pela noção de reflexividade ou de um sujeito reflexivo em Giddens (1991) ${ }^{11}$, compreendido pela premissa de que há por parte das pessoas um autoexame das próprias ações e, através dele, a possibilidade de reformulação das mais diversas práticas sociais e do próprio sujeito, tendo em vista a percepção de acesso ao pensamento e às informações, formuladas e reformuladas continuamente durante toda a existência do indivíduo.

Para Giddens (1993), os livros de autoajuda são alguns dos mecanismos da modernidade que possibilitam para os sujeitos uma maior reflexão sobre si. Em sua concepção,

${ }^{11}$ Temos conhecimentos de alguns conflitos nos pensamentos de Giddens e Foucault, principalmente quando da crítica do sociólogo às concepções sobre o sujeito e subjetividade do filósofo francês, propondo que nas pressuposições deste último o sujeito não possuiria uma ação individual e as relações de poder consistiriam apenas em sua dominação, bem como criticando as formas de subjetivação propostas por Foucault - segundo Giddens, sempre atreladas a um dispositivo em específico. A partir da leitura das obras de Foucault, torna-se difícil concordar com as críticas de Giddens, pois no centro das relações trabalhadas por Foucault estão presentes a liberdade, a resistência e a produção incessante do sujeito e de suas subjetividades a partir não de um dispositivo específico, mas em meio a uma rede histórica mais ampla e complexa. Ressalta-se, dessa forma, que a utilização das ideias de Giddens se dá levando em consideração o fato de o teórico explicitar a autoajuda como um mecanismo que induz à reflexividade ou ação reflexiva no contemporâneo, não implicando, portanto, a concordância com as críticas elencadas ao pensamento foucaultiano, que é uma das principais bases deste trabalho. 
[...] a maioria é constituída essencialmente de livros de caráter prático e correspondem a expressões de processos de reflexividade que esboçam e ajudam a conformar. Muitos são também emancipatórios: apontam para mudanças que poderiam libertar os indivíduos de influências que bloqueiam o seu desenvolvimento autônomo (GIDDENS, 1993, p. 75).

Com os momentos de reflexividade, identificados pelo autor como "uma conversa consigo mesmo" (GIDDENS, 1993, p. 103), as identidades e os sujeitos são igualmente tornados reflexivos. A proposta do teórico é que há uma nova identidade, ou novas identidades para o "eu" da modernidade, sendo estas passíveis de revisão e monitoramento recorrente. O eu torna-se "um projeto reflexivo", assim como a concepção de identidade, vista como algo "autoconstruída" pelos processos reflexivos individuais e coletivos.

O tema "conversa consigo mesmo", recorrente para os momentos de reflexividade propostos por Giddens (1993), bem como para Foucault (2006) ao abordar a questão do cuidado de si e da conversão do sujeito para si mesmo, também é comum nos enunciados das obras analisadas, algumas vezes colocados como uma "mesa redonda do eu":

SD 8 - A 9a lei da qualidade de vida - "a arte do autodiálogo: a mesa-redonda do eu" (CURY, 2007b, p. 165).

SD 9 - Não é possível sermos autores da nossa história, gerenciarmos nossos pensamentos, administrarmos nossa emoção, enfim, desenvolvermos qualidade de vida se não temos coragem e capacidade para fazer uma mesa-redonda em nosso próprio interior para debatermos com inteligência nossos próprios problemas e revisarmos nossos caminhos (CURY, 2007b, p. 169).

SD 10 - Não me procure no imenso espaço nem nos recantos da terra. Viaje para dentro de você. Eu me escondo nas vielas da sua emoção, no cerne do seu espírito... (CURY, 2007a, p. $10)$.

Na relação com estes enunciados, são promovidos agenciamentos que buscam uma subjetividade voltada para a reflexão do sujeito leitor sobre si mesmo. Com a orientação para um condicionamento ou treinamento, arregimentam o propósito das práticas a serem incorporadas para a condição de rendimentos positivos. Estas práticas postulam o engendramento de um outro tipo de cuidado de si, sendo colocadas como fontes ou caminhos da felicidade. Exterioridades diversas são discursivamente postas, engendrando produções de sentido que revelam a possibilidade de um governo de si, em meio às muitas governamentalidades, perpassado especialmente pelo desenvolvimento de uma relação de si para consigo.

Destaca-se que este "eu" que reflete sobre si mesmo que é sugerido não é uma entidade passiva, identificada somente pelas influências sociais determinantemente externas. Em oposição, é um "eu" que trama e desenvolve sua identidade, sua posiçãosujeito, pautado em sua autonomia conduzida pelos processos de autorreflexão e subjetivações efetivadas que visam a lhe dar equilíbrio. De acordo com Marín-Diaz (2015), são enunciados atravessados pela governamentalidade que visam à autogovernamentalidade, o que pode ser percebido 
[...] na produção de novas formas e reflexões para melhorar as condições de vida nas nossas sociedades - recuperação de técnicas de cuidado de si antigas ou de outras culturas, produção ampla e massiva de livros e materiais de autoajuda e, em geral, procura por métodos e formas de exercitação individuais e coletivas que ajudem a conseguir o equilíbrio que parece se encontrar no âmago do que muitos consideram ser felicidade. (MARÍN-DIAZ, 2015, p. 14)

$\mathrm{Na}$ visão da autora, as técnicas executadas na antiguidade, que visavam ao equilíbrio do sujeito, parecem ser substituídas pelas que promovem o bem-estar e a felicidade, visto como o principal bem a ser atingido na atualidade, conforme disposto pelos discursos dominantes. Para tanto, com seu discurso pedagógico, faz-se necessário que os sujeitos, atravessados pelos discursos e poderes, sendo também formados a partir destas relações que se estabelecem de múltiplas formas e podem adquirir variados sentidos, constituindo-se não por vieses unilaterais, mas a partir de um jogo, possam aprender a aprender em meio a uma série de exercitação-individualização-condução que emerge nos discursos da autoajuda, no qual o "eu" precisa embarcar e prosseguir na busca de descobertas que possam auxiliá-los a uma autocondução, vinculados a um governamento de si. Destarte, o sujeito deve moldar-se e ser, ele próprio, o responsável por seus investimentos, perdas e ganhos.

Nos moldes contemporâneos e ora investigados do cuidado de si - se assim pudermos manter a nomeação - são incorporados a felicidade e o bem-estar, os quais poderão ser atingidos a partir das técnicas enunciadas, implicando não uma mera realização, mas um autodiálogo, gerenciamento de pensamentos, administração de emoções, enfim, pela coragem de enfrentar uma mesa-redonda do eu, de fazer uma viagem para a dimensão subjetiva, com o objetivo de resolucionar os problemas identificados e revisar as rotas para se conseguir ser, efetivamente, feliz (SD's 8, 9 e 10). Trata-se de um discurso que pressupõe uma exercitação-individualização-condução, como salienta Marín-Diaz (2015). Exercitação a partir da proposição de perceber a si mesmo a partir de técnicas e treinamentos, tomar conhecimento sobre quem e como se é, para, somente assim, poder modificar-se mais uma vez com o auxílio das técnicas e treinamentos. Individualização pelo fato de que tais práticas visam promover um outro indivíduo, que efetua determinadas operações sobre si mesmo até poder transformar-se e constituir-se conforme o que é discursivamente propagado como parte da ordem; um eu que possa, por sua vez, efetivar uma outra condução de si mesmo. Uma autocondução que não cessa a sua produção, reinventando-se a partir das vivências e experiências históricas e sociais.

\section{CONSIDERAÇÕES FINAIS}

Se analisarmos brevemente os diferentes modos pelos quais os sujeitos têm buscado a felicidade, o bem-estar ou um estado de si elevado, podemos perceber que comportamentos e formas de existência dos indivíduos em se tratando destas questões diferenciam-se e agenciam modos de conduta próprios para alcançá-la em cada época (MCMAHON, 2006). Hoje, com maior força e expressão, são os discursos da autoajuda que têm produzido um imaginário sobre a felicidade e o bem-estar, concomitante à propagação de orientações voltadas para estes fins. 
Com efeito, considerando as condições de possibilidade dadas que permitiram a irrupção destes discursos a partir do arquivo de seu tempo, as análises desenvolvidas indicam as obras de Augusto Cury e os agenciamentos que produzem como mecanismo contemporâneo que trabalha com questões ligadas aos processos de subjetivação, atravessada por um governo de si e do outro que pode engendrar o interesse pelo cuidado de si, tendo em vista o posicionamento do sujeito como uma função estratégica. Com isto, percebe-se que, com seus enunciados, a literatura de autoajuda produzida por Cury trabalha aspectos referentes à felicidade que proporcionam e demandam agenciamentos subjetivos, já que os discursos possuem relações recíprocas com a construção de sentidos que se dão sob esferas subjetivas. Certamente, aqueles que buscam os discursos da autoajuda intentam um outro olhar sobre o estado de suas vidas, de forma a examinar a si mesmos através das reflexões propostas e o exercício das técnicas e treinamentos, o que não pode ser definido como negativo apenas pelo fato de muitos considerarem a autoajuda uma leitura "alienante" ou essencialmente atrelada ao mercado.

Dito isto, a questão não se centra sobre os efeitos, eficácia ou a postulação dos discursos analisados como receitas a serem seguidas. Mais do que isso, a discussão foi situada no sentido de refletir sobre os modos pelos quais, a partir de seus enunciados, a autoajuda incide na produção de subjetividades atentas e cuidadosas consigo mesmas, de modo a atualizar ou singularizar no tempo presente cuidados e práticas de si, o que no caso é feito a partir de condições de possibilidade próprias, as quais se vinculam a interesses éticos e políticos determinados.

Emerge, a partir disso, a necessidade de enfatizar que as práticas de si da atualidade não podem ser vistas como uma sucessão das práticas tradicionais, indicando um desenvolvimento ou continuidade. Ao contrário, são práticas que têm sua irrupção em meio às diversas quebras, regularidades e rupturas que compõem a história e a sociedade (FOUCAULT, 2013b). Nesta esteira, os discursos de autoajuda ora investigados indicam outros modos de governo e governamentalidade direcionados para um autogoverno, uma autocondução da própria vida, na qual é o sujeito o responsável por suas perdas e ganhos.

Nas obras analisadas, o discurso da autoajuda configura-se como dispositivo que propõe formas de subjetivação pela exterioridade que visa conduzir as vidas dos indivíduos, atuando diretamente em suas subjetividades e nos seus modos de objetivação, isto é, em sua constituição como sujeitos. Este aspecto é demonstrado a partir dos enunciados analisados, levando em conta que, como destacado anteriormente, são discursos que trabalham diretamente com a subjetividade dos leitores, atuando discursivamente na condução de suas vidas.

\section{REFERÊNCIAS}

ASSOCIAÇÃO NACIONAL DE LIVRARIAS. Diagnóstico ANL do setor livreiro. 2012. Disponível em: http://anl.org.br/web/pdf/diagnostico_setor_livreiro_2012.pdf. Acesso em: 4 jul. 2018.

MENDES, M. L. G. C.; OLIVEIRA, G. F. Treine suas emoções, supere-se, seja feliz! Uma análise discursiva do imperativo da superação e da felicidade na literatura de autoajuda. Revista Comunicação, Mídia e Consumo, v. 10, n. 29, 2013. 
CURY, A. Treinando a emoção para ser feliz. São Paulo: Academia de Inteligência, 2007a. CURY, A. 12 Semanas para mudar uma vida. São Paulo: Editora Planeta do Brasil, 2007b. DELEUZE, G. Conversações. São Paulo: Editora 34, 2008.

ECO, U. Apocalípticos e integrados. São Paulo: Perspectiva, 1979.

FERNANDES, C. Discurso e sujeito em Michel Foucault. São Paulo: Intermeios, 2012.

FOUCAULT, M. Microfísica do poder. 26. ed. São Paulo: Graal, 2013a.

FOUCAULT, M. A arqueologia do saber. 8. ed. Rio de Janeiro: Forense Universitária, 2013b.

FOUCAULT, M. A ordem do discurso. 21. ed. São Paulo: Loyola: 2011.

FOUCAULT, M. A hermenêutica do sujeito. 2. ed. - São Paulo: Martins Fontes, 2006.

FOUCAULT, M. O sujeito e o poder. In: DREYFUS, H; RABINOW, P. Michel Foucault: uma trajetória filosófica para além do estruturalismo e da hermenêutica. Rio de Janeiro: Forense Universitária, 1995. p. 229-293.

FOUCAULT, M. História da sexualidade: o cuidado de si. Edições Graal: Rio de Janeiro, 1985.

FREIRE FILHO, J. (Org.). Ser feliz hoje: reflexões sobre o imperativo da felicidade. Rio de Janeiro: Editora FGV, 2010.

GIDDENS, A. Modernidade e identidade. Rio de Janeiro: JorgeZahar, 2002.

GIDDENS, A. A transformação da intimidade: sexualidade, amor e erotismo nas sociedades modernas. São Paulo: Editora da Universidade Estadual Paulista, 1993.

GIDDENS, A. As conseqüências da modernidade. São Paulo: Editora USP, 1991.

LIPOVETSKY, G. A felicidade paradoxal: ensaio sobre a sociedade do hiperconsumo. São Paulo: Companhias das Letras, 2007.

MACHADO, R. Introdução: por uma genealogia do poder. In: FOUCAULT, M. Microfísica do poder. 26. ed. São Paulo: Graal, 2013.

MANSANO, S. R. V. Sujeito, subjetividade e modos de subjetivação na contemporaneidade. Revista de Psicologia da UNESP, v. 8, n. 2, 2009. Disponível em:

https://seer.assis.unesp.br/index.php/psicologia/article/view/946. Acesso em: 3 mar. 2021.

MARÍN-DIAZ, D. L. Autoajuda, educação e práticas de si: genealogia de uma antropotecnica. Belo Horizonte: Autêntica Editora, 2015. (Coleção Estudos Foucaultianos).

MCMAHON, D. M. Felicidade: uma história. São Paulo: Globo, 2006.

MORIN, E. Cultura de massas no século XX: neurose. 9. ed. Rio de Janeiro: Forense Universitária, 1997.

PRADO, J. L. A. Convocações biopolíticas dos dispositivos comunicacionais. São Paulo: EDUC: FAPESP, 2013.

REVEL, J. Uma subjetividade que jamais cessa de inventar-se a si própria. In: Michel Foucault - 80 anos. IHU ON-LINE, São Leopoldo, ano VI, n. 203, 2006, p. 20-27. Disponível em:

http://www.observatoriodeseguranca.org/files/foucault\%20unisinos.pdf. Acesso em: 3 mar. 2021.

RÜDIGER, F. Literatura de auto-ajuda e individualismo. Porto Alegre: Editora da Ufrgs, 1996.

$\mathrm{SCHOCH}, \mathrm{R}$. W. A história da (in)felicidade: três mil anos de busca para uma vida melhor. Rio de Janeiro: BestSeller, 2011.

SODRÉ, M. Best-seller: a literatura de mercado. São Paulo: Ática, 1985.

THOMPSON, J. B. A mídia e a modernidade: uma teoria social da mídia. Petrópolis, RJ: Vozes, 1998.

TUCHERMAN, I. Desvendando um enigma: autoajuda, mídia e biopoder. In: ROCHA, R. M.;

CASAQUI, V. (Org.). Estéticas midiáticas e narrativas do consumo. Porto Alegre: Sulina, 2012. 